\title{
Growth, photosynthetic performance and antioxidative response of 'Hass' and 'Fuerte' avocado (Persea americana Mill.) plants grown under high soil moisture
}

\author{
G. DOUPIS ${ }^{*}$, N. KAVROULAKIS ${ }^{*}$, G. PSARRAS ${ }^{*}$, and I.E. PAPADAKIS ${ }^{* *, *,+}$ \\ Hellenic Agricultural Organization "Demeter", Institute for Olive Tree, Subtropical Plants and Viticulture, \\ Agrokipio-Souda, 73100 Chania, Greece* \\ Agricultural University of Athens, Faculty of Crop Science, Laboratory of Pomology, Iera Odos 75, \\ 11855 Athens, Greece ${ }^{* *}$
}

\begin{abstract}
'Hass' and 'Fuerte' avocado plants were grown under well-watered or waterlogged conditions. Results indicated significant effects on the majority of the allometric parameters in waterlogged plants, with 'Fuerte' displaying a more pronounced growth inhibition. Waterlogged conditions caused a progressive and simultaneous decline in net photosynthetic rate and stomatal conductance, earlier in 'Fuerte' than in 'Hass'. Maximal potential quantum yield of PSII was unaffected by the soil water regime and/or variety and leaf water potential values in waterlogged plants were not more negative compared with control plants. 'Fuerte' waterlogged plants exhibited increased contents of thiobarbituric acid reactive substances, whereas oxidative injury was not detected in 'Hass'. Finally, none of the two cultivars displayed valuable antioxidant potential, as evidenced by the decreased activities of the antioxidant enzymes superoxide dismutase, guaiacol peroxidase, glutathione peroxidase, and ascorbate peroxidase.
\end{abstract}

Additional key words: cell membrane stability; chlorophyll fluorescence; gas exchange; oxidative stress; waterlogging.

\section{Introduction}

Soil is considered waterlogged whenever water content of the surface layer is at least $20 \%$ higher than the field capacity, a condition describing the water saturation at the root zone (Aggarwal et al. 2006). Waterlogging and/or flooding (i.e. shoots are also either partially or even fully submerged) of agricultural fields may develop due to anthropogenic (e.g. excessive irrigation, growing plants in low-lying areas with a high water table or in poorly drained soils, management practices that exacerbate soil degradation) or natural (e.g. highly intense rainfall, overflow of rivers, snowmelting) factors leading to altered plant metabolism and growth, increasing susceptibility to diseases, reduced crop yield or even plant mortality (Schaffer 1998, Colmer and Voesenek 2009). Furthermore, according to the "Special Report on Managing the Risks of Extreme Events and Disasters to Advance
Climate Change Adaptation" of the Intergovernmental Panel on Climate Change (IPCC), the frequency of heavy precipitation events is likely to increase in the $21^{\text {st }}$ century, enhancing the potential for soil waterlogging/flooding in many areas of the world, and thus addressing a new concept of flood risk management projects for the agricultural sector (Kundzewicz et al. 2014).

Although all higher plants require access to free water, when water saturates the root environment, plants are challenged by a significant depletion of free oxygen in the rhizosphere because of the increased microbial activity, the slow diffusion rate, and the limited solubility of oxygen in water (Irfan et al. 2010). Hypoxia refers to the reduction of oxygen below optimal concentration for the normal functioning of the plant, while anoxia describes the complete lack of oxygen in the soil. Both terms label

Received 26 July 2016, accepted 27 October 2016, published as online-first 8 December 2016.

+Corresponding author; phone: +302105294590, fax: +302105294590, e-mail: papadakis@aua.gr

Abbreviations: APX - ascorbate peroxidase; $\mathrm{Chl}$ - chlorophyll; $C_{\mathrm{i}} / C_{\alpha}$ - ratio of intracellular $\mathrm{CO}_{2}$ concentration to atmospheric $\mathrm{CO}_{2}$ concentration; DAE - days of experiment; DM - dry mass; $E$ - transpiration rate; FC - control Fuerte; $\mathrm{F}_{0}$ - minimal fluorescence yield of the dark-adapted state; $F_{m}$ - maximal fluorescence yield of the dark-adapted state; $F M-$ fresh mass; $F_{v} / F_{m}-$ maximal quantum yield of PSII photochemistry; FW - waterlogged Fuerte; GPX - glutathione peroxidase; $g_{\mathrm{s}}$ - stomatal conductance; HC - control Hass; HW - waterlogged Hass; $P_{\mathrm{N}}$ - net photosynthetic rate; POD - guaiacol peroxidase; ROS - reactive oxygen species; SOD - superoxide dismutase; TBARS - thiobarbituric acid reactive substances; $\psi_{\mathrm{m}}-$ soil matric potential; $\psi_{\mathrm{w}}-$ water potential. 
the transfer from aerobic to anaerobic metabolism in roots, with dramatic restrictions to ATP synthesis and carbohydrate economy (Voesenek and Sasidharan 2013). Anaerobic lactic acid and ethanol fermentation (BaileySerres and Voesenek 2008), cytoplasmic acidification (Colmer and Voesenek 2009), accumulation of reduced soil components, such as $\mathrm{Mn}^{2+}, \mathrm{Fe}^{2+}$, and $\mathrm{S}^{2-}$, and carboxylic acids to toxic concentrations (Irfan et al. 2010), modification of plant hormone biosynthesis (Kramer and Boyer 1995), stomatal closure and reductions in photosynthetic rate (Pimentel et al. 2014), excessive formation of reactive oxygen species (ROS) (Blokhina et al. 2003), and a decrease in the hydraulic conductivity of roots (Tournaire-Roux et al. 2003) are the main features caused by lack of soil oxygen. The severity of waterlogging effects depends on plant species, the stage of plant development, the duration of the waterlogging event, and the depth of the water level, but if air contact cannot be reestablished, the exhaustion of sugars and the energy deficit lead to severe tissue damage, reduced root and shoot growth and reproductive disorders and, eventually, to mortality (Drew 1997).

Avocado (Persea americana Mill.) is a profitable tree crop with a total world production more than 4.5 million tons (Bost et al. 2013). Several economically important cultivars, such as cv. 'Hass' and cv. 'Fuerte', are grown under Mediterranean climate conditions, with main commercial avocado orchards located in California, Chile, south-western Australia, and the northern parts of the Mediterranean basin (Carr 2013, González-Sánchez et al. 2013). Moreover, avocado has recently become a dynamic crop at the island of Crete, Greece, where it is grown on more than 800 ha. In avocado, the root system does not spread much beyond the tree canopy and the majority of roots, which function for water and nutrient uptake, are mainly restricted to the upper $60 \mathrm{~cm}$ of the soil profile (Lahav et al. 2013). Roots are extremely suberized, with low hydraulic conductivity, few or no root hairs, high oxygen demand and poor water-uptake efficiency

\section{Materials and methods}

Plant material and treatments: Forty-eight, two-year-old avocado plants (Persea americana Mill.), cv. 'Hass' and 'Fuerte', grafted onto Zutano seedling rootstock were used in this experiment, which was conducted under nethouse conditions at the facilities of the Institute of Olive Tree, Subtropical Plants and Viticulture in Chania, Crete, Greece $\left(35^{\circ} 32^{\prime} 00^{\prime \prime} \mathrm{N}, 24^{\circ} 04^{\prime} 09^{\prime \prime} \mathrm{E}\right)$. The plants were grown in 35-L pots filled with a slightly alkaline sandy loam soil.

Two soil water regimes were applied during the experimental period (October-July): (1) a control, wellwatered treatment (for 'Fuerte' - FC and for 'Hass' - HC), where the plants were irrigated manually when soil matric potential $\left(\psi_{\mathrm{m}}\right)$ value reached $-0.03 \mathrm{MPa}$ [average value from tensiometers (Irrometer Company, Riverside, CA, USA), which were installed at $20 \mathrm{~cm}$ depth in five
(Ferreyra et al. 2007). Furthermore, mechanisms of waterlogging tolerance through anatomical and morphological adaptations (aerenchyma formation, development of hypertrophic stem lenticels and/or adventitious roots) have not been observed in avocado trees (Schaffer et al. 2013). These characteristics classify avocado among the tree species most sensitive to root hypoxia with physiological and growth responses reported shortly after soil becomes waterlogged (Schaffer 1998). Low soil oxygen content due to poor soil drainage is often accompanied by wilting, reduced leaf size, and leaf abscission (Schaffer et al. 2006), restriction of vegetative and root growth (Gil et al. 2007), and root necrosis (Schaffer et al. 2013). Schaffer (1998) reported that a few days of flooding can result in avocado tree death as a result of extensive root system damage. Root decay caused by waterlogging can be exacerbated by Phytophthora root rot (caused by the soilborne fungal pathogen Phytophthora cinnamomi Rands), the major disease of avocado worldwide (Reeksting et al. 2014). Physiological responses of avocado tree to oxygen deficiency in the rooting zone include reductions in leaf gas exchange parameters, such as net $\mathrm{CO}_{2}$ assimilation rate $\left(P_{\mathrm{N}}\right)$, stomatal conductance $\left(g_{\mathrm{s}}\right)$, transpiration $(E)$, and ratio of internal to atmospheric $\mathrm{CO}_{2}$ concentrations $\left(C_{\mathrm{i}} / C_{\alpha}\right)$ (Schaffer et al. 2013, Sanclemente et al. 2014), reduced PSII efficiency (Reeksting et al. 2014), and water and nutrient uptake restrictions (Gil et al. 2012).

Although the generation of ROS is a well-known effect of excessive water in the soil (Blokhina et al. 2003), to our best knowledge, there is no study regarding the consequences of low soil oxygen content-induced oxidative stress and elucidating the ability to induce the antioxidant defense mechanism in avocado tree. This study: (1) addressed this lack by investigating potential antioxidative responses under excessive soil moisture conditions and (2) conducted a comprehensive evaluation of the growth and physiological responses of the avocado cultivars 'Hass' and 'Fuerte' to soil waterlogging.

randomly selected pots] and (2) a waterlogging treatment (for 'Fuerte' - FW and 'Hass' - HW) where each 35-L pot was submerged in an about half-sized (20-L) plastic bucket filled with tap water. To maintain a constant water level, the buckets were refilled as needed. Each treatment was applied to twelve uniform plants of each avocado variety.

Measurements of gas-exchange characteristics $\left(P_{\mathrm{N}}, g_{\mathrm{s}}\right)$ were carried out after $1,6,17,29,72,155$, and 274 days of the experiment (DAE). Leaf water potential $\left(\psi_{\mathrm{w}}\right)$ and maximal potential quantum yield of PSII $\left(\mathrm{F}_{\mathrm{v}} / \mathrm{F}_{\mathrm{m}}\right)$ were also recorded on $274 \mathrm{DAE}$. One day later (275 DAE), plants were harvested for the determination of allometric parameters, and leaf and root samples were taken for the determination of lipid peroxidation level (TBARS), hydrogen peroxide concentration, and antioxidant enzyme activities. 
Allometric parameters: At the end of the experiment (275 DAE), 12 plants (replicates) of each treatment were removed and the diameter of the trunk was measured $10 \mathrm{~cm}$ above (scion's diameter) and $10 \mathrm{~cm}$ below (rootstock's diameter) the grafting line. Shoots formed during the experiment were separated into stems and leaves. Total stem length per plant was calculated as the sum of the lengths of all new stems. Total leaf area per plant was measured using a $L I-3100 C$ area meter ( $L I-C O R$ Biosciences Inc., Lincoln, Nebraska, USA). Subsequently, stems and leaves were weighted for the determination of fresh mass (FM), while stem and leaf total dry mass (DM) was determined after the material was dried in an oven at $70^{\circ} \mathrm{C}$ to a constant mass.

Leaf gas exchange, chlorophyll (Chl) fluorescence and leaf water potential: Net $\mathrm{CO}_{2}$ assimilation rate $\left(P_{\mathrm{N}}\right)$ and stomatal conductance $\left(g_{\mathrm{s}}\right)$ were recorded with a $\mathrm{Li}-6400$, portable photosynthesis system (LiCor Bioscience Inc., Lincoln, Nebraska, USA) in the morning (between 09:30 and 11:00 h) at a light-saturated photosynthetic photon flux (PPFD greater than $1,000 \mu \mathrm{mol} \mathrm{m} \mathrm{m}^{-2} \mathrm{~s}^{-1}$ ) and a reference $\mathrm{CO}_{2}$ concentration of $380 \mu \mathrm{mol} \mathrm{mol}{ }^{-1}$. The measurements were taken on one healthy and fully expanded leaf from five plants $(n=5)$ per treatment. Chl fluorescence was measured with a portable fluorometer (Mini PAM, Walz, Effeltrich, Germany), on the same leaves used for gas-exchange determinations. Prior the measurement of Chl fluorescence, the leaves were dark-adapted for 20-30 min, to ensure oxidation of the plastoquinone pool. Measurements of the minimal $\left(\mathrm{F}_{0}\right)$ and maximal $\left(\mathrm{F}_{\mathrm{m}}\right)$ fluorescence yield were performed, thus allowing the determination of variable to maximal fluorescence ratio $\left(\mathrm{F}_{\mathrm{v}} / \mathrm{F}_{\mathrm{m}}\right)$, which represents a measure of the maximum efficiency of PSII in darkness. Finally, leaf water potential $\left(\psi_{\mathrm{w}}\right)$ was measured on mature leaves from the middle of the last season shoots using a pressure chamber (PMS Instrument Company, Corvallis, Oregon, USA) and following the recommendations of Scholander et al. (1965).

Enzymatic antioxidant activity, lipid peroxidation and hydrogen peroxide: Superoxide dismutase (SOD, EC 1.15.1.1), guaiacol peroxidase (POD, EC 1.11.1.7), glutathione peroxidase (GPX, EC 1.11.1.9), and ascorbate peroxidase (APX, EC 1.11.1.11) activities were determined in four samples $(n=4)$ of leaves and roots per treatment and variety. Plant material was collected at the end of the experiment and was immediately frozen at $-80^{\circ} \mathrm{C}$. The extraction medium consisted of $0.1 \mathrm{M}$ potassium phosphate buffer $(\mathrm{pH} \mathrm{7.6)}$, containing $1 \mathrm{mM}$ ethylenediaminetetraacetic acid disodium salt, $0.5 \mathrm{mM}$ ascorbate (in the case of the APX assay), and 1\% polyvinylpolypyrrolidone. Plant tissue $(0.3 \mathrm{~g})$ was homogenized in $1.5 \mathrm{ml}$ of the extraction buffer and the homogenate was centrifuged at $13,000 \times g$ for $30 \mathrm{~min}$. The supernatant was used for activity assays. The absorbance of the crude enzyme extracts was measured with a Hitachi
U-1100 spectrophotometer (Hitachi Ltd., Tokyo, Japan). Total SOD activity was assayed according to the methodology of Becana et al. (1986). One unit of SOD activity (U) was defined as the amount of enzyme that produced a $50 \%$ inhibition of nitroblue tetrazolium (NBT) reduction. Guaiacol POD assay was performed using the method described by Zhang (1992). POD activity was measured by the increase in absorbance following the oxidation of guaiacol at $470 \mathrm{~nm}$. One unit of POD was defined as $1 \mu \mathrm{mol}$ of guaiacol oxidized $\mathrm{min}^{-1}$. The determination of GPX activity was based on the method of Drotar et al. (1985). Activity was measured by the decrease in absorbance at $340 \mathrm{~nm}$ for $10 \mathrm{~min}$. One unit of enzyme activity was defined as the amount of enzyme required to oxidize $1 \mathrm{nmol}$ of NADPH $\mathrm{min}^{-1}$. APX activity was determined, according to Nakano and Asada (1981), by measuring the oxidation rate of ascorbate at $290 \mathrm{~nm}$. One unit of APX was defined as the amount of enzyme that oxidized $1 \mu \mathrm{mol}$ ascorbate $\mathrm{min}^{-1}$. All enzyme activities were calculated on fresh mass basis.

Leaf tissue $(0.5 \mathrm{~g})$ obtained from the same leaves that were used for the antioxidant enzyme assays, was homogenized with $5 \mathrm{ml}$ trichloroacetic acid (TCA) $0.1 \%$ $(\mathrm{w} / \mathrm{v})$ in an ice bath. The homogenate was centrifuged at $10,000 \times g$ for 30 min and the supernatant was used for the determination of thiobarbituric acid reactive substances (TBARS) and $\mathrm{H}_{2} \mathrm{O}_{2}$ content. Lipid peroxidation was determined by quantifying the TBARS content as described by Hodges et al. (1999) with minor modifications. In particular, $1 \mathrm{ml}$ of the supernatant was added to an equal volume of either (1) $20 \%$ (w/v) TCA solution containing $0.01 \%$ butylated hydroxytoluene or (2) $20 \%(\mathrm{w} / \mathrm{v}) \mathrm{TCA}$ solution containing $0.65 \%(\mathrm{w} / \mathrm{v})$ TBA and $0.01 \%$ butylated hydroxytoluene. The mixture was incubated at $95^{\circ} \mathrm{C}$ for $30 \mathrm{~min}$, quickly cooled and centrifuged at 10,000 $\times \mathrm{g}$. The absorbance was read at $532 \mathrm{~nm}$ with the values for nonspecific absorption at $600 \mathrm{~nm}$ and $440 \mathrm{~nm}$ subtracted. TBARS content was expressed as as nmol g-1 $(\mathrm{FM}) . \mathrm{H}_{2} \mathrm{O}_{2}$ content was determined according to the methodology of Alexieva et al. (2001). Absorbance measurements were carried out by above spectrophotometer at $390 \mathrm{~nm}$ using a solution consisting of TCA $0.1 \%$ and pure catalase reagent as a blank, to ensure zero interference. The $\mathrm{H}_{2} \mathrm{O}_{2}$ content was calculated by comparing the reads with a standard curve obtained from different concentrations of $\mathrm{H}_{2} \mathrm{O}_{2}$. Final concentration was expressed as $\mu \mathrm{mol} \mathrm{g}^{-1}(\mathrm{FM})$.

Data analysis: The experimental design was a $2 \times 2$ factorial, with two avocado varieties and two soil water regimes. Totally, 48 plants were used, i.e. 12 control plants and 12 high soil moisture-treated ones per variety ('Hass' and 'Fuerte'). Data were analyzed by a two-way analysis of variance $(A N O V A)$ to assess interactions between soil moisture (SM) treatments and varieties (V), using the SPSS 15.0 statistical package (SPSS Inc., Chicago, USA). For the comparison of the means, the Student's $t$-test as well as the Duncan's multiple range test were employed $(P<0.05)$. 
For gas-exchange characteristics, treatment means were further compared using the 'repeated measures' feature of SPSS 15.0. Calculation of correlation coefficients $\left(R^{2}\right)$ and

\section{Results}

In our study, scion's diameter, total stem length, total leaf and stem DM, and total leaf area were significantly higher in control plants than that of waterlogged plants for both varieties. Rootstock's diameter was also negatively affected by the waterlogging conditions but only in 'Fuerte' (Fig. 1). Furthermore, a significant soil moisture $\times$ variety interaction effect was detected in total leaf DM, because of the greater percentage reduction observed in stressed 'Fuerte' plants (76\%) compared to those of 'Hass' (45\%) (Fig. 1C).

High soil moisture affected both $P_{\mathrm{N}}$ and $g_{\mathrm{s}}$ values in a similar way, as shown by the parallel decline in both parameters, as the experiment progressed (Fig. $2 A, B$ ). $P_{\mathrm{N}}$ significantly decreased in waterlogged plants, which exhibited an average reduction in $P_{\mathrm{N}}$ values, throughout the experimental period, of about $21 \%$ compared with control treatments. The largest reduction in $P_{\mathrm{N}}$ values was recorded in the FW plants, being $28 \%$ of FC values. The figures preparation were performed using GraphPad Prism 5.0 software (GraphPad Software Inc., La Jolla, California, USA).

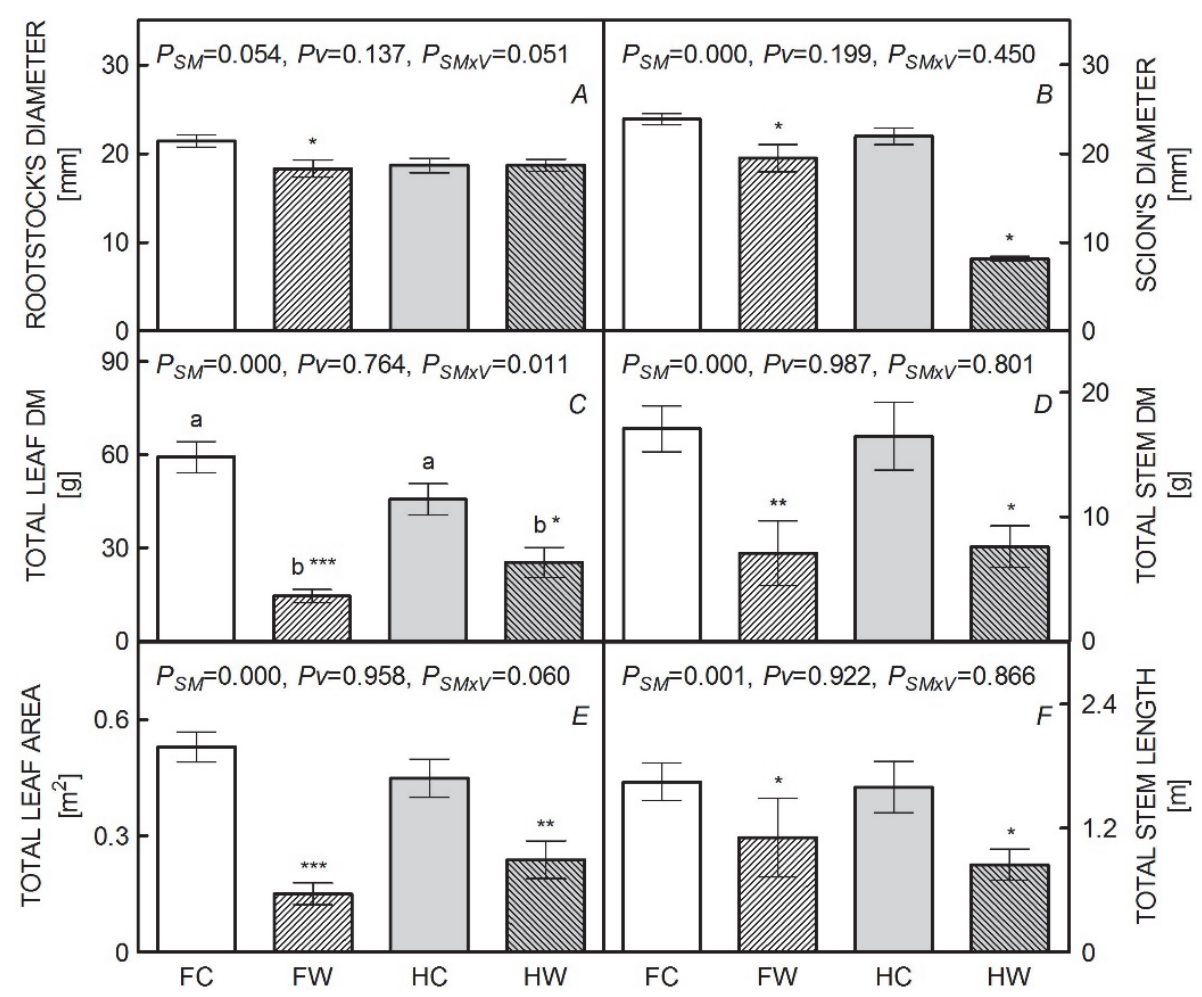

Fig. 1. The effect of soil moisture, variety, and their combination on various allometric parameters of 'Hass' and 'Fuerte' avocado plants. Data represent average values \pm SE $(n=12)$. For each parameter, different letters above bars indicate significant differences at $P<0.05$ (Duncan's multiple range test). Asterisks indicate significant differences between control and waterlogged plants of the same variety, at $P<0.05\left(^{*}\right), P<0.010\left(^{* *}\right)$ or $P<0.001\left(^{* * *}\right)$; (Student's $t$-test). $P \mathrm{SM}-$ significance of the soil moisture level; $P \mathrm{~V}-$ significance of the different varieties; $P_{\mathrm{SMx}}-$ significance of the soil moisture $\times$ variety interaction. FC - Fuerte control; FW - Fuerte waterlogged; $\mathrm{HC}$ - Hass control; HW - Hass waterlogged. 


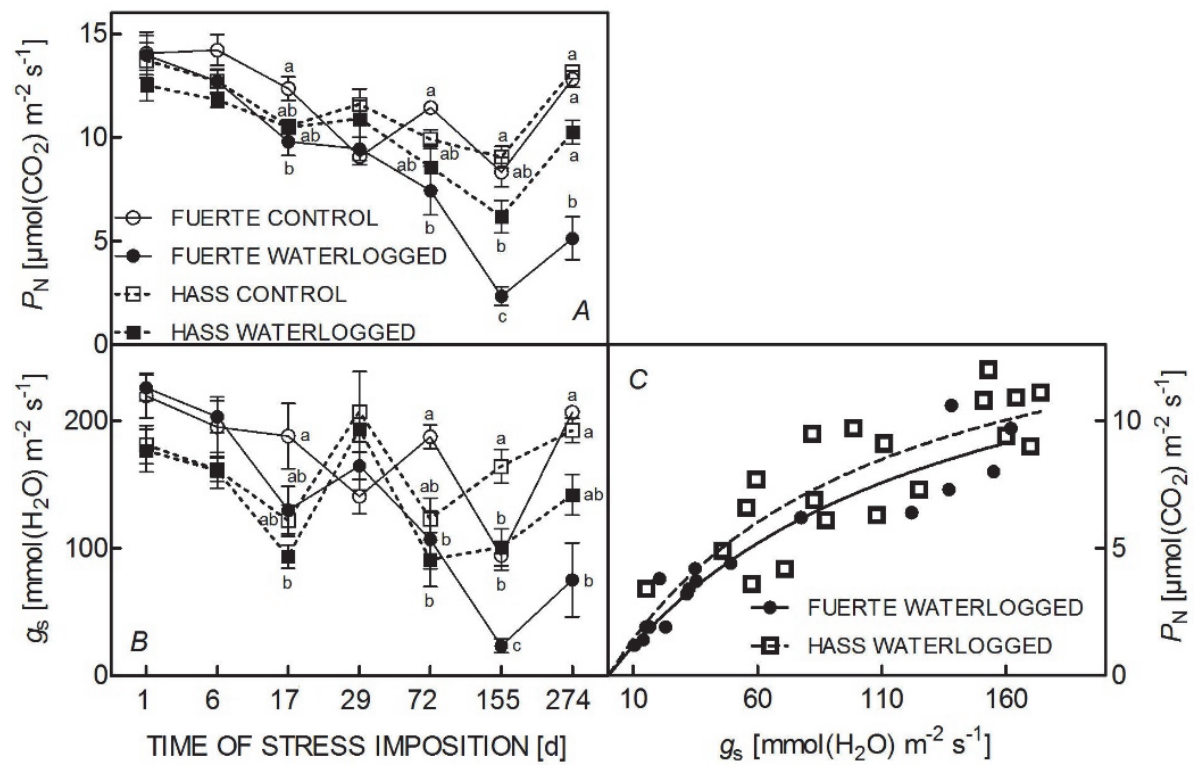

Fig. 2. Variation of net photosynthetic rate $\left(P_{\mathrm{N}}, A\right)$ and stomatal conductance $\left(g_{\mathrm{s}}, B\right)$ in leaves of 'Hass' and 'Fuerte' avocado plants during the experimental period (each value represents the average of five replicates \pm SE) and the relationship between $g_{\mathrm{s}}$ and $P_{\mathrm{N}}$ for the high soil moisture treatment at the end of the stress imposition $(C)$. For each parameter and day after the stress imposition, means of $P_{\mathrm{N}}$ and $g_{\mathrm{s}}$ followed by the same letter were not significantly different at $P<0.05$ (Duncan's multiple range test). Nonlinear regressions of $P_{\mathrm{N}}$ with $g_{\mathrm{s}}$ : 'Fuerte' Waterlogged: $\mathrm{y}=2.93 \ln (\mathrm{x})-6.31, R^{2}=0.90$ and 'Hass' Waterlogged: $\mathrm{y}=3.45 \ln (\mathrm{x})-7.73, R^{2}=0.72$. Fitted lines were statistically significant at $P<0.001$.

A downregulation of APX, GPX, and POD activity was revealed in leaves of waterlogged trees in both cultivars during the last day of the stress imposition, whereas the activation of SOD isoforms under excessive soil moisture was not so prominent (Fig. 4). Of the four enzymes studied, a significant increase was detected only in APX activity in roots of FW, whereas GPX, POD, and

\section{Discussion}

At soil redox values below $+350 \mathrm{mV}$, oxygen begins to disappear from the soil, roots of flooded and/or waterlogged plants are exposed to anaerobic conditions, and various changes in the overall plant metabolism are induced in order to preserve survival under low energy availability (Irfan et al. 2010). Avocado is considered a waterlogging-sensitive tree species with tree growth and metabolism negatively impacted by low soil oxygen content (Schaffer et al. 2006). In our study, excessive soil moisture for nine months significantly affected the majority of the allometric parameters examined, except for rootstock's diameter in 'Hass' variety (Fig. 1). Stressed plants were shorter, with smaller total leaf area and decreased biomass production compared with controls. However, we noted that, although no significant differences were found between the two cultivars in terms of vegetative growth $\left(P_{\mathrm{v}}>0.05\right)$, 'Fuerte' plants imposed to reduced soil oxygen (FW treatment) exhibited a higher percentage decrease in the majority of the allometric traits examined in relation to HW treatment. This relative
SOD activity in roots of waterlogged plants did not differ significantly compared with control ones (Table 1, Fig. 4).

The extent of oxidative membrane damage was significantly higher in FW than that in HW (Fig. 5). TBARS and $\mathrm{H}_{2} \mathrm{O}_{2}$ content in leaves of FW were four times and three times higher, respectively, than that in HW plants.

maintenance of plant growth was reported in 'Hass' avocado, a variety of the Guatemalan race that is replacing the traditional variety 'Fuerte' in most places with a Mediterranean type of climate (Carr 2013); it might imply that 'Hass' could perform slightly better during a prolonged period with high soil moisture.

In contrast to some other subtropical species (e.g. mango tree), there are no reports on morphological and anatomical adaptations of avocado under waterlogging conditions, and hence physiological modifications could probably relieve the stress of insufficient oxygen supply and sustain metabolic activity and growth. As seen in different woody and herbaceous species (Malik et al. 2001, Pang et al. 2004, Gimeno et al. 2012, Reeksting et al. 2014) "wet soil"-induced reductions of photosynthesis occur due to stomatal or nonstomatal limitations, which are related to the biochemical reactions of photosynthesis. In addition, Castonguay et al. (1993) suggested that reduced respiratory activity in roots implies a feedback mechanism, when a production of photosynthates is limited, 


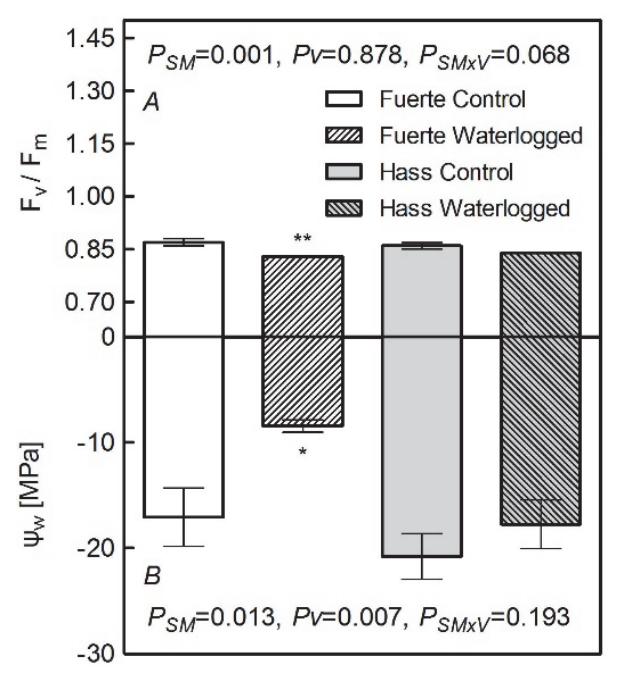

Fig. 3. Effect of soil moisture on maximal potential quantum yield of PSII $\left(\mathrm{F}_{\mathrm{v}} / \mathrm{F}_{\mathrm{m}}\right)$ and leaf water potential $\left(\psi_{\mathrm{w}}\right)$ during the last day of the experimental period. Values are the average of five replicates \pm SE. For each parameter different letters denote significant differences at $P<0.05$ (Duncan's multiple range test). Asterisks indicate significant differences between control and waterlogged plants of the same variety, at $P<0.05\left(^{*}\right), P<0.010$ $(* *)$ or $P<0.001(* * *)$; (Student's $t$-test). $P_{\mathrm{SM}}-$ significance of the soil moisture level; $P_{\mathrm{V}}-$ significance of the different varieties; $P_{\mathrm{SMxV}}-$ significance of the soil moisture $\times$ variety interaction. exacerbating $P_{\mathrm{N}}$ decline in plants subjected to hypoxia. In the present study, avocado tree induced stomatal closure with a subsequent downregulation of the photosynthetic machinery (Fig. 2A,B). Closing the stomata limits the ability of the plant to capture $\mathrm{CO}_{2}$, thus reducing photosynthetic enzyme substrate and lowering the $P_{\mathrm{N}}$. The simultaneous and parallel decline of $P_{\mathrm{N}}$ and $g_{\mathrm{s}}$ in flooded plants, under limited rhizosphere oxygen concentrations, indicates that the decline in net photosynthesis is mainly a consequence of stomatal limitation (Farquhar and Sharkey 1982), and that the inhibition of key metabolic processes is not detectable even when $g_{\mathrm{s}}$ dropped to minimum values during the latter stages of the experiment (Fig. 2C, 155 and 274 DAE). In addition, at the end of the experiment (274 $\mathrm{DAE}), \mathrm{F}_{\mathrm{v}} / \mathrm{F}_{\mathrm{m}}$ values were around 0.85 and very similar in the waterlogged as well as in the control plants of both varieties (Fig. 3A), supporting the absence of photochemical and biochemical irreversible impairments of the photosynthetic apparatus. Our results do not agree with Schaffer et al. (1992) and Reeksting et al. (2014) who attributed changes in $P_{\mathrm{N}}$ in flooded avocado plants to nonstomatal limitations associated with metabolic impairment of photosynthetic processes. However, in any case, (1) different scion-rootstock combinations, (2) the extent and duration of anaerobic conditions, (3) the temporal separation between these physiological modifications, and (4) the presence of Phytophthora root rot in the substrate

Table 1. Significance of the soil moisture level $\left(P_{\mathrm{SM}}\right)$, significance of the different varieties $\left(P_{\mathrm{V}}\right)$; significance of the soil moisture $\times$ variety interaction effect on antioxidant enzymes $\left(P_{\mathrm{SMxV}}\right)$ activity in leaves and roots of 'Hass' and 'Fuerte' avocado plants. Values lower than 0.05 indicate significant effects. SOD - superoxide dismutase; APX - acsorbate peroxidase; GPX - glutathione peroxidase; POD - guaiacol peroxidase.

\begin{tabular}{lllllllll}
\hline Source of variance & \multicolumn{1}{l}{ Leaves } & \multicolumn{1}{c}{ Roots } \\
\hline & SOD & APX & GPX & POD & SOD & APX & GPX & POD \\
PSM $_{\text {PV }}^{0.225}$ & 0.000 & 0.000 & 0.000 & 0.695 & 0.944 & 0.357 & 0.603 \\
PSMxV & 0.288 & 0.090 & 0.469 & 0.131 & 0.493 & 0.006 & 0.023 & 0.386 \\
& 0.963 & 0.129 & 0.122 & 0.820 & 0.264 & 0.004 & 0.619 & 0.803 \\
\hline
\end{tabular}

should be considered when determining if waterlogginginduced reductions in photosynthesis occur due to stomatal or nonstomatal factors in avocado.

It is also worth noting that the stomatal closure of both waterlogged treatments occurred without a decrease in leaf water potential (Fig. 3B). Furthermore, FW plants, which exhibited greater sensitivity during vegetative growth, also displayed the higher overall $\psi_{\mathrm{w}}$ values at the end of the waterlogging period. Our findings indicate that, in avocado, stomatal response to high soil moisture was independent of leaf water status and in addition, reduced transpiratory losses following stomatal closure could be considered as an adaptive mechanism to prevent leaf dehydration (Irfan et al. 2010). Similar behavior has been observed in other plant species, such as kiwi fruit (Savé and Serrano 1986), mango tree (Larson et al. 1991), oak species (Dreyer et al. 1991), and citrus seedlings (Rodríguez-Gamir et al. 2011), and it was attributed to abscisic acid accretion in leaves, losses of root hydraulic conductance, increase in $\mathrm{CO}_{2}$ concentration caused by import of gas from the soil, and the involvement of growth regulators, such as ethylene, auxin, and gibberellins. In the current study, maintaining a stable leaf hydration did not improve the assimilation potential, and the underlying growth potential of the stressed avocado trees; additionally the hyperbolic equation characterizing the relationship between $P_{\mathrm{N}}$ and $g_{\mathrm{s}}$ (Fig. 2C) revealed insignificant, but consistent larger $P_{\mathrm{N}}$ reduction than that of $g_{\mathrm{s}}$ (and thus a lower water-use efficiency) in FW treatment, suggesting that a lower degree of stress was affecting 'Hass' avocado. 


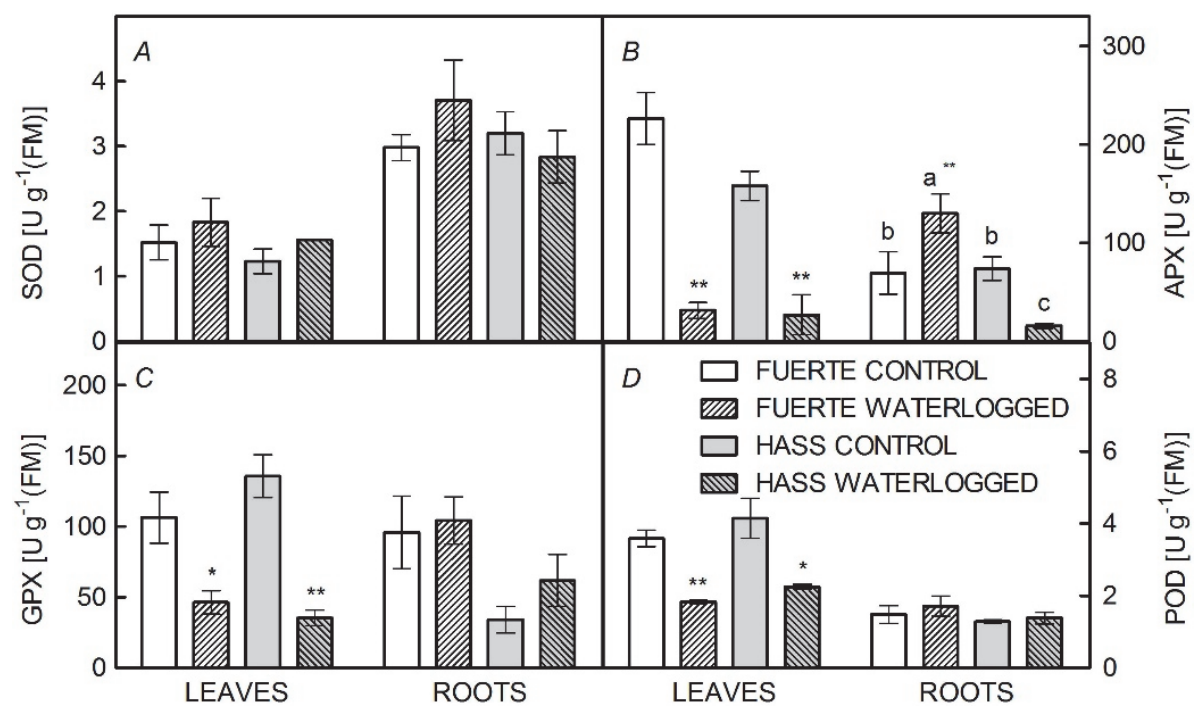

Fig. 4. Effects of soil moisture, variety and their combination on superoxide dismutase (SOD), APX, GPX, and POD at the end of the experimental period. Data represent average values \pm SE $(n=4)$. For each enzyme and plant tissue (leaves, roots), means followed by the same letter were not significantly different at $P<0.05$ (Duncan's multiple range test). Asterisks indicate significant differences between control and waterlogged plants of the same variety, at $P<0.05(*), P<0.010(* *)$ or $P<0.001$ (***); (Student's $t$-test).

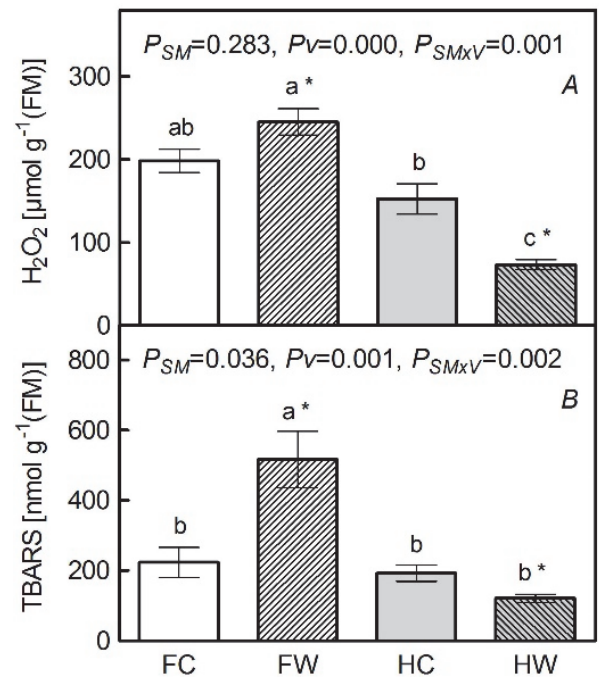

Fig. 5. The effects of soil moisture, variety and their combination on thiobarbituric acid reactive substances (TBARS) and $\mathrm{H}_{2} \mathrm{O}_{2}$ content in leaves of 'Hass' and 'Fuerte' avocado plants, at the end of the experimental period. Data represent average values \pm SE $(n=4)$. For each parameter, different letters indicate significant differences at $P<0.05$ (Duncan's multiple range test). Asterisks indicate significant differences between control and waterlogged plants of the same variety, at $P<0.05(*), P<0.010$ $(* *)$ or $P<0.001(* * *)$; n.s. - insignificant differences $(P>0.05)$ (Student's $t$-test). $P_{\mathrm{SM}}$ - significance of the soil moisture level; $P_{\mathrm{V}}-$ significance of the different varieties; $P_{\mathrm{SMxV}}$ - significance of the soil moisture $\mathrm{x}$ variety interaction. $\mathrm{FC}$ - Fuerte control; FW - Fuerte waterlogged; HC - Hass control; HW - Hass waterlogged.

The better photosynthetic performance exhibited by 'Hass' variety under high soil moisture was also validated by the progressive decline of $P_{\mathrm{N}}$ values in HW treatment, compared to the prolonged inhibition of carbon assimilation in $\mathrm{FW}$ treatment as the experimental period progressed.

Several authors have reported increased accumulation of ROS under hypoxic/anoxic conditions (for a review, see Blokhina et al. 2003). Waterlogging-induced limitation of $\mathrm{CO}_{2}$ fixation and lack of soil oxygen provoke the overreduction of the photosynthetic electron transport chain forming superoxide radicals $\left(\mathrm{O}_{2}{ }^{\bullet-}\right)$ and singlet oxygen species $\left({ }^{1} \mathrm{O}_{2}\right)$ in chloroplasts and $\mathrm{H}_{2} \mathrm{O}_{2}$ in mitochondria. Moreover, possible sources for hypoxia-stimulated enhanced ROS production involve acetaldehyde formation and lipoxygenase reaction. Disturbances in the equilibrium between ROS production and scavenging under stress conditions induce both protective responses and cellular damage (Gill and Tuteja 2010). A variety of enzymatic, such as SOD, CAT, and peroxidases, and nonenzymatic scavengers, such as ascorbate, glutathione, carotenoids, phenolic compounds, and tocopherols, play an active role in controlling the concentration of ROS, while the excessive accumulation of ROS and molecules due to the limited or ineffective antioxidant response results in oxidized damage to lipids, proteins, and nucleic acids (Halliwell and Gutteridge 1989). In our study, the content of TBARS produced during peroxidation of membrane lipids - a general marker of oxidative stress - at the end of the experimental period was significantly increased in $\mathrm{FW}$, indicating excess soil moisture-induced oxidative injury (Fig. 5B). In contrary, 'Hass' avocado responded to waterlogging with a significantly lower extent of lipid peroxidation, with TBARS values relatively depressed in HW plants with respect to controls, revealing a considerable adaptability of 'Hass' to ROS pressure under high soil moisture conditions. Increasing oxidative stress is also 
supported by increasing concentration of leaf $\mathrm{H}_{2} \mathrm{O}_{2}$ content in FW plants, while the absence of oxidative stress in HW plants is coupled with a reduction in $\mathrm{H}_{2} \mathrm{O}_{2}$ generation (Fig. 5A). Our results were in agreement with reports of Bansal and Srivastava (2012) and Alam et al. (2010) who concluded that there is a direct correlation between $\mathrm{H}_{2} \mathrm{O}_{2}$ accumulation and lipid peroxidation, leading to oxidative injury during waterlogging in pigeon pea and soybean, respectively.

While in other tree species the activation of the antioxidant defense system as indicative of tolerance or sensitivity under soil waterlogging conditions has been studied, showing a direct relationship between increased antioxidant enzymes activity and stress tolerance (Blokhina et al. 2003, Arbona et al. 2008, Hossain et al. 2009, Porto et al. 2013), no information exists concerning avocado tree antioxidant response under low soil oxygen concentrations. In this work, antioxidant enzyme activities remained unchanged in roots and decreased significantly in leaves of waterlogged plants (Fig. 4). Our results suggest that: (1) the increased contents of ROS did not stimulate the cellular protective mechanism to mitigate damages in FW, (2) 'Hass' avocados were not subjected to oxidative stress after a prolonged period under high soil moisture, and (3) the activation of the major enzymes involved in the antioxidant system under waterlogging conditions did not constitute a generic response, but might depend on plant species, cultivar, stress intensity, and duration. Plants under hypoxic conditions typically use a complex antioxidative defense system consisting of several nonenzymatic and enzymatic components responsible for the scavenging and/or detoxification of the toxic oxygen radicals (Blokhina et al. 2003). According to Chugh et al. (2011), the major cause of oxidative stress is

\section{References}

Aggarwal P.K., Kalra N., Chander S., Pathak H: InfoCrop: A dynamic simulation model for the assessment of crop yields, losses due to pests, and environmental impact of agroecosystems in tropical environments. I. model description. Agr. Syst. 89: 1-25, 2006.

Alam I., Lee D., Kim K. et al.: Proteome analysis of soybean roots under waterlogging stress at an early vegetative stage. J. Biol. Sci. 35: 49-62, 2010.

Alexieva V., Sergiev I., Mapelli S., Karanov E.: The effect of drought and ultraviolet radiation on growth and stress markers in pea and wheat. - Plant Cell Environ. 24: 1337-1344, 2001.

Arbona V., Hossain Z., López-Climent M.F. et al.: Antioxidant enzymatic activity is linked to waterlogging stress tolerance in citrus. - Physiol. Plantarum 132: 452-466, 2008.

Bailey-Serres J., Voesenek L.A.: Flooding stress: acclimations and genetic diversity. - Annu. Rev. Plant Biol. 59: 313-339, 2008.

Bansal R., Srivastava J.P.: Antioxidative defense system in pigeonpea roots under waterlogging stress. - Acta Physiol. Plant. 34: 515-522, 2012.

Becana M., Aparicio-Tejo P., Irigoyen J.J. et al.: Some enzymes of hydrogen peroxide metabolism in leaves and root nodules of the disability of the scavenging system to metabolize the toxic oxygen radicals due to either increased ROS formation or decreased activity of the antioxidant enzymes. Our results revealed a differential response to oxidative stress in the two avocado cultivars, with 'Hass' cultivar exhibiting an increased protection, which did not correlate positively with the activation of the enzymes studied and thus, suggesting that different mechanisms might be involved in the enhancement of the antioxidant defense.

In conclusion, conditions of high water soil moisture significantly affected vegetative growth and photosynthetic capacity of both avocado cultivars. No evidence was found that the alteration of leaf gas exchange following a prolonged period of excessive soil moisture was associated with biochemical limitations to photosynthesis and/or cell membrane damage, as a result of $\mathrm{H}_{2} \mathrm{O}_{2}$ accumulation, and similarly, no evidence was found that stomatal closure was initiated by a loss of leaf hydration. We also suggest that the four antioxidant enzymes studied (SOD, POD, GPX, and APX) had no major antioxidative function in avocado trees imposed to low soil oxygen supply. In addition, the results of our study allowed us to speculate that 'Hass' cultivar possesses a certain level of waterlogging tolerance as indicated by: (1) the less pronounced effects on allometric parameters in $\mathrm{HW}$, (2) the maintenance of a better photosynthetic performance in HW, and (3) the ROS damage avoidance in HW. The aforementioned 'Hass' cultivar traits might be of large interest for avocado management programs in waterlogging-prone agricultural areas and, thus, should be in the agenda of further research as they could provide a better insight into avocado's adaptability to specific regions.

Medicago sativa. - Plant Physiol. 82: 1169-1171, 1986.

Blokhina O., Virolainen E., Fagerstedt K.V.: Antioxidants, oxidative damage and oxygen deprivation stress: A review. Ann. Bot.-London 91: 179-194, 2003.

Bost J.B., Smith N.J.H., Crane J.H.: History, distribution and uses. - In: Schaffer B., Wolstenholme B.N., Whiley A.W. (ed.): The Avocado: Botany, Production and Uses. Pp. 10-30. CABI Publishing, Wallingford 2013.

Carr M.K.V.: The water relations and irrigation requirements of avocado (Persea americana Mill.): A Review. - Exp. Agr. 49: 256-278, 2013

Castonguay Y., Nadeau P., Simard R.R.: Effects of flooding on carbohydrate and ABA levels in roots and shoots of alfalfa. Plant Cell Environ. 16: 695-702, 1993.

Chugh V., Kaur N., Gupta A.K.: Evaluation of oxidative stress tolerance in maize (Zea mays L.) seedlings in response to drought. - Indian J. Biochem. Bio. 48: 47-53, 2011.

Colmer T.D., Voesenek L.A.: Flooding tolerance: Suites of plant traits in variable environments. - Funct. Plant Biol. 36: 665681, 2009.

Drew M.C.: Oxygen deficiency and root metabolism: Injury and acclimation under hypoxia and anoxia. - Annu. Rev. Plant 
Phys. 48: 223-250, 1997.

Dreyer E., Colin-Belgrand M., Biron P.: Photosynthesis and shoot water status of seedlings from different oak species submitted to waterlogging. - Ann. Sci. Forest. 48: 205-214, 1991.

Drotar A., Phelps P., Fall R.: Evidence for glutathione peroxidase activities in cultured plant cells. - Plant Sci. 42: 35-40, 1985.

Farquhar G.D., Sharkey T.D.: Stomatal conductance and photosynthesis. - Annu. Rev. Plant Phys. 33: 317-345, 1982.

Ferreyra R.E., Selles G.V., Maldonado P.B. et al.: Effects of environment, leaf characteristics and measuring methodology on stem water potential in avocado trees (Persea americana Mill.). - Agr. Tec. 67: 182-188, 2007.

Gil P.M., Bonomelli C., Schaffer B. et al.: Effect of soil waterto-air ratio on biomass and mineral nutrition of avocado trees. - J. Soil Sci. Plant Nutr. 12: 609-630, 2012.

Gil P.M., Schaffer B., Gutiérrez S.M., Li C.: Effect of waterlogging on plant water status, leaf gas exchange and biomass of avocado. - Proc. VI ${ }^{\text {th }}$ World Avocado Congress. Pp. 14. Viña del Mar 2007.

Gill S.S., Tuteja N.: Reactive oxygen species and antioxidant machinery in abiotic stress tolerance in crop plants. - Plant Physiol. Bioch. 48: 909-930, 2010.

Gimeno V., Syvertsen J.P., Simon I. et al.: Interstock of 'valencia' orange affects the flooding tolerance in 'verna' lemon trees. HortScience 47: 403-409, 2012.

González-Sánchez M.Á., de Vicente A., Pérez-García A. et al.: Evaluation of the effectiveness of biocontrol bacteria against avocado white root rot occurring under commercial greenhouse plant production conditions. - Biol. Control 67: 94-100, 2013.

Halliwell B., Gutteridge J.M.C.: Free Radicals in Biology and Medicine. Pp. 368-373. Oxford University Press, Oxford 1989.

Hodges D.M., DeLong J.M., Forney C.F., Prange R.K.: Improving the thiobarbituric acid-reactive-substances assay for estimating lipid peroxidation in plant tissues containing anthocyanin and other interfering compounds. - Planta 207: 604-611, 1999.

Hossain Z., López-Climent M.F., Arbona V. et al.: Modulation of the antioxidant system in citrus under waterlogging and subsequent drainage. - J. Plant Physiol. 166: 1391-1404, 2009.

Irfan M., Hayat S., Hayat Q. et al.: Physiological and biochemical changes in plants under waterlogging. - Protoplasma 241, 317, 2010.

Kramer P.J., Boyer J.S.: Water Relations of Plants and Soils. Pp. 147-157. Elsevier Academic Press, London, 1995.

Kundzewicz Z.W., Kanae S., Seneviratne S.I. et al.: Flood risk and climate change: Global and regional perspectives. Hydrolog. Sci. J. 59: 1-28, 2014.

Lahav E., Whiley A.W., Turner D.W.: Irrigation and mineral nutrition. - In: Schaffer B., Wolstenholme B.N., Whiley A.W. (ed.): The Avocado: Botany, Production and Uses, $2^{\text {nd }}$ ed. Pp. 301-341. CABI Publishing, Wallingford 2013.

Larson K.D., Schaffer B., Davies F.S.: Flooding, leaf gas exchange and growth of mango in containers. - J. Am. Soc. Hortic. Sci. 116: 156-160, 1991.

Malik A.I., Colmer T.D., Lambers H., Schortemeyer M.: Changes in physiological and morphological traits of roots and shoots of wheat in response to different depths of waterlogging.
- Aust. J. Plant Physiol. 28: 1121-1131, 2001.

Nakano Y., Asada K.: Hydrogen peroxide is scavenged by ascorbate-specific peroxidase in spinach chloroplasts. - Plant Cell Physiol. 22: 867-880, 1981.

Pang J., Zhou M., Mendham N., Shabala S.: Growth and physiological responses of six barley genotypes to waterlogging and subsequent recovery. - Aust. J. Agr. Res. 55: 895-906, 2004.

Pimentel P., Almada R.D., Salvatierra A. et al.: Physiological and morphological responses of Prunus species with different degree of tolerance to long-term root hypoxia. - Sci. Hortic.Amsterdam 180: 14-23, 2014

Porto B.N., Alves J.D., Magalhães P.C. et al.: Calciumdependent tolerant response of cell wall in maize mesocotyl under flooding stress. - J. Agron. Crop Sci. 199: 134-143, 2013

Reeksting B.J., Taylor N.J., van den Berg N.: Flooding and Phytophthora cinnamomi: Effects on photosynthesis and chlorophyll fluorescence in shoots of non-grafted Persea americana (Mill.) rootstocks differing in tolerance to Phytophthora root rot. - S. Afr. J. Bot. 95: 40-53, 2014.

Rodríguez-Gamir J., Ancillo G., González-Mas M.C. et al.: Root signalling and modulation of stomatal closure in flooded citrus seedlings. - Plant Physiol. Bioch. 49: 636-645, 2011.

Sanclemente M.A., Schaffer B., Gil P.M. et al.: Pruning after flooding hastens recovery of flood-stressed avocado (Persea americana Mill.) trees. - Sci. Hortic.-Amsterdam 169: 27-35, 2014.

Savé R., Serrano L.: Some physiological and growth responses of kiwi fruit (Actinidia chinensis) to flooding. - Physiol. Plantarum 66: 75-78, 1986.

Schaffer B.: Flooding responses and water-use efficiency of subtropical and tropical fruit trees in an environmentallysensitive wetland. - Ann. Bot.-London 81: 475-481, 1998.

Schaffer B., Andersen P.C., Ploetz R.C.: Responses of fruit trees to flooding. - In: Janick J. (ed.): Horticultural Reviews, Vol. 13. Pp. 257-313, John Wiley \& Sons, New York 1992.

Schaffer B., Davies F.S., Crane J.H.: Responses of subtropical and tropical fruit trees to flooding in calcareous soil. HortScience 41: 549-555, 2006.

Schaffer B., Gil P.M., Mickelbart M.V., Whiley A.W. Ecophysiology. - In: Schaffer B., Wolstenholme B.N., Whiley A.W. (ed.): The Avocado: Botany, Production and Uses, $2^{\text {nd }}$ ed. Pp. 168-199. CABI Publishing, Wallingford 2013.

Scholander P.F., Bradstreet E.D., Hemmingsen E.A., Hammel H.T.: Sap pressure in vascular plants. - Science 148: 339-346, 1965.

Tournaire-Roux C., Sutka M., Javot H. et al.: Cytosolic pH regulates root water transport during anoxic stress through gating of aquaporins. - Nature 425: 393-397, 2003.

Voesenek L.A., Sasidharan R.: Ethylene- and oxygen signallingdrive plant survival during flooding. - Plant Biol. 15: 426-435, 2013.

Zhang X.Z.: The measurement and mechanism of lipid peroxidation and SOD, POD and CAT activities in biological system. - In: Zhang X.Z. (ed.): Research Methodology of Crop Physiology. Pp. 208-211. Agriculture Press, Beijing 1992. 